\title{
Exploring the Application of Best Practices to TA Awards: One University's Approach
}

Laurel Willingham-McLain, Deborah L. Pollack

Duquesne University

This chapter explores how to adapt best practices from the general literature on teaching awards in higher education to graduate student teaching assistant (TA) awards. Although most criteria apply, they must be fitted to the career stage and aspirations of TAs. The Duquesne University Graduate Student Award for Excellence in Teaching serves as a case study demonstrating how these practices can be modified to both recognize excellent teaching and promote the professional development of graduate student instructors.

Several articles provide guidelines for faculty teaching awards. According to Menges (1995), for example, for a teaching award to be considered effective, it must pass the three tests of "selection validity," to address accurate selection and representativeness; "faculty motivation," to ensure an increase among the number of faculty striving to meet award criteria; and "public perception," whereby an external audience has noted the institution's dedication to rewarding exemplary teaching.

In their overview article, Svinicki and Menges (1995) put forth 10 guidelines. They propose that the program be aligned with the institution's mission and be based on "sound assessment practices" and "research-based teaching competencies" (p.110) in order to minimize bias and the common objection that such awards are popularity contests. Svinicki and Menges also advise that the award not replace proper remuneration for teaching, that the winners 
contribute to faculty development on their campus, and that the program be flexible and open to change.

Carusetta (2001) reports that whereas $70 \%$ of two-year and liberal arts colleges and $96 \%$ of research institutions have teaching awards, empirical research on the effects of such awards on both the individual and institutional levels is sparse in the literature. Chism and Szabo (1997) provide a list of six areas for studying the impact of teaching awards, including whether the awards actually fulfill their most commonly stated goals of affirming good teachers, rewarding good teachers, improving teaching and learning, and improving the campus climate for both learning and teaching.

Unfortunately, although many institutions have TA awards, the literature on these is thin. Our review of the literature, as well as personal communications with Karron Lewis and Laura Border (December 3 and December 7, 2004), former and current editors of the Journal of Graduate Teaching Assistant Development, yielded only one brief article by Langford (1987). Many faculty award practices clearly apply to TA awards, but we conjecture that the goals and impact of TA awards differ sufficiently from typical faculty awards to merit their own study.

First, since most graduate students only teach at their universities for a few years, the institution will not have the long-term benefit of those particular individuals' teaching effectiveness. In fact, by the time they receive a teaching award many TAs have nearly completed their graduate studies. The projected outcome of the award thus shifts from promoting excellence in teaching at the home institution to a focus on supporting the professional development of TAs as they prepare to leave. TA awards might best serve, then, not only to recognize symbolic achievement, or a "job well done" (Chism, 2005, p. 320), but also to engage TAs in a formative process whereby nominees reflect on their teaching and prepare an evidence-based dossier.

Whereas faculty may decry the extensive effort it takes to develop a solid dossier (Menges, 1995), graduate students with teaching aspirations need to prepare a statement of teaching philosophy, and sometimes a teaching portfolio, for their academic job search. Indeed, the demand is increasing internationally for faculty to provide teaching portfolios for such reasons as applying for entry-level positions, awards, teaching grants, and promotion and tenure (Schonwetter, Sokal, Friesen, \& Taylor, 2002). Moreover, even if a candidate is not asked to submit a teaching philosophy, the ability to articulate one's teaching practice is generally expected in the oral interview. Graduate students who are not preparing for academic carcers can nonetheless benefit from the process of reflecting on their teaching experiences and learning to implement changes based on feedback. 
Some faculty view teaching awards as "low stakes activities" (Chism, 2005, p. 320; Menges, 1995, p. 5), compared to the pressure to achieve more highly coveted honors such as publications and research grants. Whereas many faculty may perceive a teaching award to be a drop in the bucket, the stakes are often much greater for graduate students preparing to enter the competitive academic job market. TAs may be more motivated to prepare the submission hoping that the award will highlight their teaching abilities to prospective employers.

In addition to the formative emphasis we propose for TA awards, attention needs to be paid to establishing appropriate criteria and standards. For example, drawing from Schonwetter et al.'s (2002) "rubric for evaluating Teaching Philosophy Statements," Chism (2005) lists tentative standards for judging teaching effectiveness for faculty, whereby "good/excellent" evidence of participation in the scholarship of teaching and learning would include activities such as a "presentation of teaching work at conferences or workshops," and "exemplary" evidence would include the "above, plus at least one publication on the scholarship of teaching and learning" (p. 323). Although some graduate students achieve this, it should certainly not be expected of them at this career stage. The question then arises as to how to define evidence of excellence in teaching at the graduate student level.

Our investigation of about 20 TA teaching awards via the World Wide Web indicates wide variability in the evidence used to judge effective teaching. For example, although most of these require at least one faculty nomination or recommendation, additional materials include a CV, graduate transcripts, student evaluations, sample syllabi, peer or student evaluations, classroom observation data, an essay about a teaching challenge, a statement of teaching philosophy, and full teaching portfolios. Based on a review of 118 teaching awards in higher education, Chism (2005) suggests that

the reliance by most awards programs on secondary forms of evidence (such as appraisals by others) rather than primary evidence (such as course materials, teaching philosophy statements, or samples of student work) indicates reluctance on the part of many committees to actually engage the evidence firsthand. (p. 320)

Although Chism includes several TA awards in her analysis (personal communication, December 1, 2004), she does not highlight the differences between TA and faculty awards. Preliminarily, we have found that many TA awards require both primary and secondary forms of evidence.

Finally, although they are not addressed in the literature, we would suggest the following benefits of TA awards. Possible advantages to nominees 
participating in the award process include guided reflection, career preparation, CV enhancement, and practice developing a sound statement of teaching philosophy and presenting teaching materials. Of course, winners have additional benefits such as university-wide recognition at a ceremony, letters, certificates, and monetary prizes. The institution profits from having TAs set the standard for their peers about what constitutes good teaching, and from their inspiring less experienced TAs to develop the habit of reflecting on and improving their teaching.

TA award programs should certainly be informed by the guidelines in the general literature on teaching awards in higher education. At the same time, we need to examine the potential uniqueness of their purpose, the level of motivation among nominees, the perceived importance of the award, the types of evidence (primary, secondary, or both), and the criteria and standards best used to judge nominees. In order to illustrate this process, we will discuss how we developed a TA award program at Duquesne University.

\section{Establishment of the Award}

In 2001, we began exploring the possibility of a university-wide teaching award for TAs to recognize the major contribution they make to teaching and learning on our campus. We had been conferring a faculty teaching award for a decade, but TAs were not eligible nor was it fitted to their experiences. Only one school had a TA award, and it was based solely on faculty nomination.

A start-up committee consisting of TAs, faculty members, deans, and Center for Teaching Excellence (CTE) staff met the year prior to implementation. Based on the literature describing effective teaching awards as well as our understanding of the general career stage and aspirations of Duquesne University graduate students, we agreed upon the following statement to describe our Graduate Student Award for Excellence in Teaching:

The purpose of the award is to promote and reward teaching effectiveness by current graduate students and to provide award nominees with training on how to present evidence of teaching excellence.

Knowing that many of our TAs are planning to pursue academic careers and that they are likely to be hired at teaching-oriented institutions, we chose a two-step process whereby faculty write nominations, and nominees then compile a teaching portfolio as the award dossier. 
We chose a significantly more intensive formative component than we had seen at other institutions. Nominations are made in early October, and nominees then have three months to attend CTE sessions on portfolio development, write, reflect, have their courses observed by faculty, and meet with CTE staff for feedback on their portfolios.

We established three award criteria by integrating principles from two research domains: teaching awards and successful practices of junior faculty. Our purpose for the latter was to reward and encourage practices that are reported to enhance the transition to academic careers.

- Mastery of the basics of teaching (preparation, clear communication of course content, effective use of time, availability to students, feedback on learning, and fairness in grading)

- Professional interactions about teaching with faculty and graduate student colleagues

- Ability to reflect on teaching and apply what they learn from feedback

For the first criterion, the committee chose basic college teaching and articulated six indicators of mastery at this level. Note that we do not consider these to be sufficient indicators for faculty awards. Our Duquesne faculty Creative Teaching Award focuses, for example, on innovation in teaching supported by evidence of student learning.

The second criterion reflects Boice's (1991) observation that new faculty who thrive regularly interact with their colleagues about teaching. Research on faculty socialization suggests that this important process begins in the graduate school years (Austin \& Wulff, 2004), and that interaction among graduate students, their peers, and their professors in a variety of formssuch as seeking and receiving feedback on teaching practices-is crucial to forging a professional identity (Austin, 2002). Unfortunately, research on graduate student development continually points to a lack of systematic interaction and mentoring in most graduate programs (Austin, 2002). Thus, in order to encourage potential award nominees to seek out these types of socialization opportunities, we have provided a list of what these interactions might include. These range from meeting with incoming TAs, mentoring junior peers, and providing departmental TA leadership, to offering campuswide presentations on teaching.

The final critcrion recognizes that teaching is a scholarly activity. Good teachers reflect on their teaching and gather feedback from their students, peers, and faculty. They use feedback to discover their underlying assumptions about teaching and learning, think critically about how their practices 
are aligned with those assumptions, and develop goals for their future development as teachers (Brookfield, 1995). This criterion ensures that nominees engage in that process, thereby further supporting the formative purpose of the award as a professional development activity.

In order to balance the selectivity of the award between being a high honor, and being attainable to a reasonable number of TAs, the start-up committee established a 1:50 ratio of awards to TAs; that is, 4 awards for roughly 200 TAs. Given the vastly different roles TAs play (e.g., from leading science labs to taking sole responsibility for a course), we chose to address the differences in TA training and level of responsibility by designating a specific number of awards per school: two in the humanities and social sciences, one in natural sciences, and one in pharmaceutical sciences. In so doing, we addressed Menges' (1995) test of representativeness, that "recipients fairly represent the variety of fields and instructional situations" (p. 7).

We structured the nomination process such that nominees who complete the teaching portfolio are publicly honored and receive a letter from CTE detailing the significance of their nomination. The start-up committee intentionally constructed a nomination process worthy of a $\mathrm{CV}$ line for entry-level faculty candidates. In addition, the four award winners receive $\$ 500$ and a letter from the provost. All involved receive a book on teaching, often chosen according to their specific interests.

The award is sponsored by the Office of the Provost and administered by CTE. A representative committee of seven TAs and faculty members evaluate the portfolios, recommend the winners, address procedural questions, and conduct ongoing reflection on the award process. The CTE associate director chairs the committee, and the instructional consultant for TAs serves as advisor; neither has a vote.

The award we designed serves both symbolic and formative purposes. To be nominated in the first place, TAs have to have demonstrated excellence in teaching, but to become eligible to win the award, they must also participate in a process of coaching and feedback by disciplinary faculty as well as CTE staff.

\section{The Award Dossier}

The award process begins with a letter of nomination by a faculty member in the TA's department. The nomination form includes contact information, a confirmation of eligibility, an indication of additional recommendations (optional), instructions for the nomination letter itself, and signatures of the 
chair and dean. Nominators initial a line saying they have provided the nominee with a copy of the nomination and understand that it will be included in the teaching portfolio. The nomination is not confidential. The details of our award can be found at http://www.cte.duq.edu/awards/taawards/guidelines .html.

We request that the nomination address all three criteria (basic teaching, interactions about teaching, and reflection based on feedback) and that it describe the TA's teaching. Simple rankings and superlative statements are not helpful to a committee choosing winners from a pool of excellent TAs. Nomination letters initiate our TA award process and serve as the leading document of the portfolio. Letters that provide thorough description for each criterion help the evaluating committee make better informed decisions; vague or off-topic letters raise questions and pose difficulty in comparing nominees. Chism (2005) notes that "in $74 \%$ of the cases calling for letters of nomination or support, the letter writers are not given any instructions about what their letter should address" (p. 317). We have found that committee members carefully examine the nomination letters, and that nominators are more consistently following our guidelines.

The dossier itself consists of both primary and secondary materials. At the committee's request, we revised the original order so that all secondary materials come first in the portfolio. Though not standard procedure for teaching portfolios, this adaptation makes the dossier easier for committee members to evaluate.

The second required element is a faculty member's observation of the TA teaching. We require a standard form that includes items pertaining directly to the indicators of basic-level teaching excellence: evidence of preparation, organization and use of class time, communication of course content, opportunity for student participation and practice, and specific advice for how the TA might improve his or her teaching. Note the integration of formative processes. Nominees are permitted to include peer observations using the same form. The collaborative nature of our award process was underscored recently when two nominees from the same department observed each other and included the reports in their dossiers.

Primary materials form the majority of the portfolio, beginning with the statement of teaching philosophy. This statement serves as an introduction to the instructor's reflections, presentation of teaching materials, and student evaluation summaries. Ideally, the themes nominees choose to highlight reflect both their teaching practices and the feedback students give them. An exemplary portfolio presents a coherent picture of their teaching beliefs, 
strengths, and areas for development. Though beyond the nominee's control, ideally this coherence extends to the secondary materials as well.

A descriptive list of postsecondary courses taught provides a context for the TA's teaching experience. Finally, a summary of their professional interactions about teaching indicates the degree to which they engage in public discussions of teaching, and take the opportunity to provide and receive feedback.

The evaluation committee consists of TAs and faculty who generally have no experience in evaluating teaching portfolios. So far, in spite of the considerable work required, they have stepped up to the task and appear to appreciate the rich picture that a portfolio can provide. In order to help the committee evaluate the dossiers, we have created evaluation guidelines (retrievable online at http://www.cte.duq.edu/awards/taawards/evaluation.pdf). The first column indicates the three major criteria (including the six indicators of teaching excellence), the second column tells where evidence of these criteria might be found, and the final column provides samples of what these criteria might look like. Committee members systematically discuss the extent to which nominees have met each criterion.

Two final points bear mentioning. Nominees who do not win the award may be renominated. Sometimes their success is a matter of gaining more experience as teachers. Nominees are welcome to request general feedback on the committee's deliberation after the award celebration. This practice is aligned with the formative purpose of the award. Several TAs have made use of this feedback to improve their portfolios, either after being renominated or in preparing for the job search.

\section{Ongoing Reflection on Our Award Process}

The committee serves not only to evaluate dossiers but to reflect on the process and answer questions posed by various stakeholders. The following is a sample of questions we have addressed in the first three years.

- Is it truly an award if the nominee has to work so hard? Upon experiencing the process, the questioners generally come to the conclusion that indeed it is an honor to receive such intense mentoring as well as public recognition.

- How can we be equitable within schools when TAs have differing roles and training across departments, and some programs only have MA degrees? Do English doctoral students have an unfair advantage because they are more 
experienced writers and also receive systematic mentoring? We address this through the guidance provided by CTE in that nominees can consult with CTE staff as often as they want. Because of the clarity and thoroughness of her portfolio, an MA student has won even though she competed with more experienced peers.

- How can we teach nominees to communicate across the university? For example, one year, committee members were critical of the attempts nominees made to incorporate metaphors into their teaching philosophies. The nominees had innocently followed basic teaching philosophy how-to articles in using metaphors to think about their teaching. Now we guide nominees away from using metaphors that others may find trite.

- What counts as teaching? Our guidelines state, "Teaching is broadly defined to include traditional independent teaching of a class, online teaching, lab instruction, recitation leadership, and teaching done in pairs of instructors." The nominator must verify that the nominee has met the criterion of having taught two courses with the official status of TA. Beyond that, our nominees have had teaching experience in various contexts, such as the Writing Center.

- What if a graduate student has never had a TA position but teaches as adjunct faculty for our department? In this case, we determined that the person was not eligible because we wanted to maintain the focus on graduate students as teachers and risked opening up the process to all adjunct faculty.

- Given the high stakes of being a nominee, what happens if a nominee does not complete a full teaching portfolio according to the award guidelines? In one case, the nominee did not do the most basic work required and was informed behind the scenes that he would not be considered an official nominee.

- What happens when none of the nominees from a particular school provide indication of excellence in all three criteria in their portfolio? The committee chose to maintain high standards and, with the provost's approval, to withhold the $\$ 500$ award from the school that year and instead to honor the TAs only as official nominees. This was a difficult decision because the incompleteness of the dossiers is not completely the fault of individual TAs but can reflect on gaps in their school's mentoring of TAs. 


\section{Initial Evaluation of the Award's Impact}

We plan to examine the impact of our award on winners, nominees, committee members, departments, and the institution. We have begun by asking all those involved each year to comment on the value of the award process and to provide suggestions for improving it. In this, the third year, we already see signs of the award's impact.

Awardees and nominees have provided this feedback: They appreciate having three months, including the semester break, to work on the dossier with checkpoints along the way. They are grateful for the mentoring and the opportunity to think about teaching, and are greatly relieved to have begun compiling materials for the job search in advance. One nominee requested that there be more interaction among nominees beyond the introductory meeting because there was too little time to look at each others' work at the ceremony. Another recommended showcasing the portfolios in a library display with excerpts on handouts for people to take and read.

All involved enjoyed the public recognition at the award ceremony and reception. We haven't yet contacted the awardees and nominees once they have left Duquesne, but one reported having successfully used the portfolio to get a position at a well-regarded state university.

Nominees are giving back to the university by providing leadership to their peers in their departments, through CTE, and through the award committee. Award committee members appreciate discussing teaching across disciplines and learning from each others' practices. Also, graduate students have the unique opportunity of serving on a university-wide committee reporting to the provost.

Nominees and committee members alike have returned to their programs requesting increased mentoring, distribution of responsibilities, and systematic feedback from students and faculty on their teaching. This is a slow process but one that can have a dramatic impact on both TAs and the students they teach. The award has also influenced other award programs in the university. For example, one department has required the submission of a teaching portfolio for their $\mathrm{TA}$ award, a requirement which was modeled after our university-wide award.

At the institutional level, graduate students are honored for their teaching excellence at the same ceremony as the faculty and receive the same amount of money as a prize. This ceremony is well attended, and we intend to give the message that TAs contribute in significant ways to teaching and learning at Duquesne and that they conduct their teaching and reflection on it in scholarly ways. 


\section{Conclusion}

We are fortunate to have had literature on effective teaching awards at our disposal in establishing the Graduate Student Award for Excellence in Teaching at Duquesne University. In the process, however, we have recognized that not all faculty award criteria are appropriate to graduate students. We have thus explored ways in which these criteria might best be adapted to TA awards. Though far from flawless, our TA award serves as an example of one way best practices can be applied both to honor excellent basic-level teaching and to guide graduate students as they seek to enter the professoriate. We are currently planning research that will assess the impact of our TA services overall. In particular, those TAs who have been involved in the award process as nominees, winners, or committee members will be contacted and interviewed about how their involvement with the award has fostered their professional development at Duquesne and beyond.

\section{Note}

We thank Academic Associate Vice President Dorothy Frayer and Provost Ralph Pearson for supporting our TA award, and Steven H. Wells and Fr. David Sedor for their role in its early research and development.

\section{References}

Austin, A. E. (2002). Assessing doctoral students' progress along developmental dimensions. Paper presented at the annual meeting of the Association for the Study of Higher Education, Sacramento, CA. Retrieved May 22, 2005, from http:// www.carnegiefoundation.org/CID/ashe/Assessing_doctoral_students.pdf

Austin, A. E., \& Wulff, D. H. (2004). The challenge to prepare the next generation of faculty. In D. H. Wulff, A. E. Austin, \& Associates, Paths to the professoriate: Strategies for enriching the preparation of future faculty (pp. 3-16). San Francisco, CA: Jossey-Bass.

Boice, R. (1991). Quick starters: New faculty who succeed. In M. Theall \& J. Franklin (Eds.), New dircctions for teaching and learning: No. 48. Effective practices for improving teaching (pp. 111-121). San Francisco, CA: Jossey-Bass.

Brookfield, S. D. (1995). Becoming a critically reflective teacher. San Francisco, CA: Jossey-Bass. 
Carusetta, E. (2001). Evaluating teaching through teaching awards. In C. Knapper \& P. Cranton (Eds.), New directions in teaching and learning: No. 88. Fresh approaches to the evaluation of teaching (pp. 31-40). San Francisco, CA: JosseyBass.

Chism, N. V. N. (2005). Promoting a sound process for teaching awards programs: Appropriate work for faculty development centers. In S. Chadwick-Blossey \& D. R. Robertson (Eds.), To improve the academy: Vol. 23. Resources for faculty, instructional, and organizational development (pp. 314-330). Bolton, MA: Anker.

Chism, N. V. N., \& Szabo, B. L. (1997). Teaching awards: The problem of assessing their impact. In D. DeZure \& M. Kaplan (Eds.), To improve the academy: Vol. 16. Resources for faculty, instructional, and organizational development (pp. 181-200). Stillwater, OK: New Forums Press.

Langford, T. A. (1987). Recognizing outstanding teaching. In N. V. N. Chism (Ed.), Institutional responsibilities and responses in the employment and education of teaching assistants: Readings from a national conference (pp. 132-133). Columbus, OH: The Ohio State University, Center for Teaching Excellence.

Menges, R. J. (1995). Awards to individuals. In M. D. Svinicki \& R. J. Menges (Eds.), New directions in teaching and learning: No. 65. Honoring exemplary teaching (pp. 3-9). San Francisco, CA: Jossey-Bass.

Schonwetter, D. J., Sokal, L., Friesen, M., \& Taylor, K. L. (2002). Teaching philosophies reconsidered: A conceptual model for the development and evaluation of teaching philosophy statements. International Journal for Academic Development, $7(1), 83-97$.

Svinicki, M. D., \& Menges, R. J. (1995). Consistency within diversity: Guidelines for programs to honor exemplary teaching. In M. D. Svinicki \& R. J. Menges (Eds.), New directions in teaching and learning: No. 65. Honoring exemplary teaching (pp. 109-113). San Francisco, CA: Jossey-Bass. 